\title{
ASO Visual Abstract: Lymphovascular Invasion-Traditional but Vital and Sensible Prognostic Factor in Early Gastric Cancer
}

\author{
Seohee Choi, MD ${ }^{1,2}$, Jeong Ho Song, MD ${ }^{1,2}$, Sejin Lee, MD ${ }^{1,2}$, Minah Cho, MD ${ }^{1,2}$, Yoo Min Kim, MD, PhD ${ }^{1,2}$, \\ Hyoung-Il Kim, MD, PhD ${ }^{1,2}$, and Woo Jin Hyung, MD, $\mathrm{PhD}^{1,2}$ (D) \\ ${ }^{1}$ Department of Surgery, Yonsei University College of Medicine, Seoul, Republic of Korea; ${ }^{2}$ Gastric Cancer Center, \\ Yonsei Cancer Center, Yonsei University Health System, Seoul, Republic of Korea
}

Lymphovascular invasion (LVI) in gastric cancer haslongbeen suggested as a poor prognostic indicator. Our study sought to evaluate the prognostic effect of LVI inpatients withearlygastric cancer (https://doi.org/10.1245/ s10434-021-10224-6) and determined that earlygastric cancer with LVI is indeed associated with poor prognosis and frequent recurrence.
DISCLOSURES Woo Jin Hyung reports receiving research grants from Medtronic and GC Pharma. He is also the chief executive officer ofHutomand holds stocks in the company. He provided consultancy services to Ethicon and Verb Surgical outside the submitted work, and received lecture fees from Stryker. Seohee Choi, Jeong Ho Song,

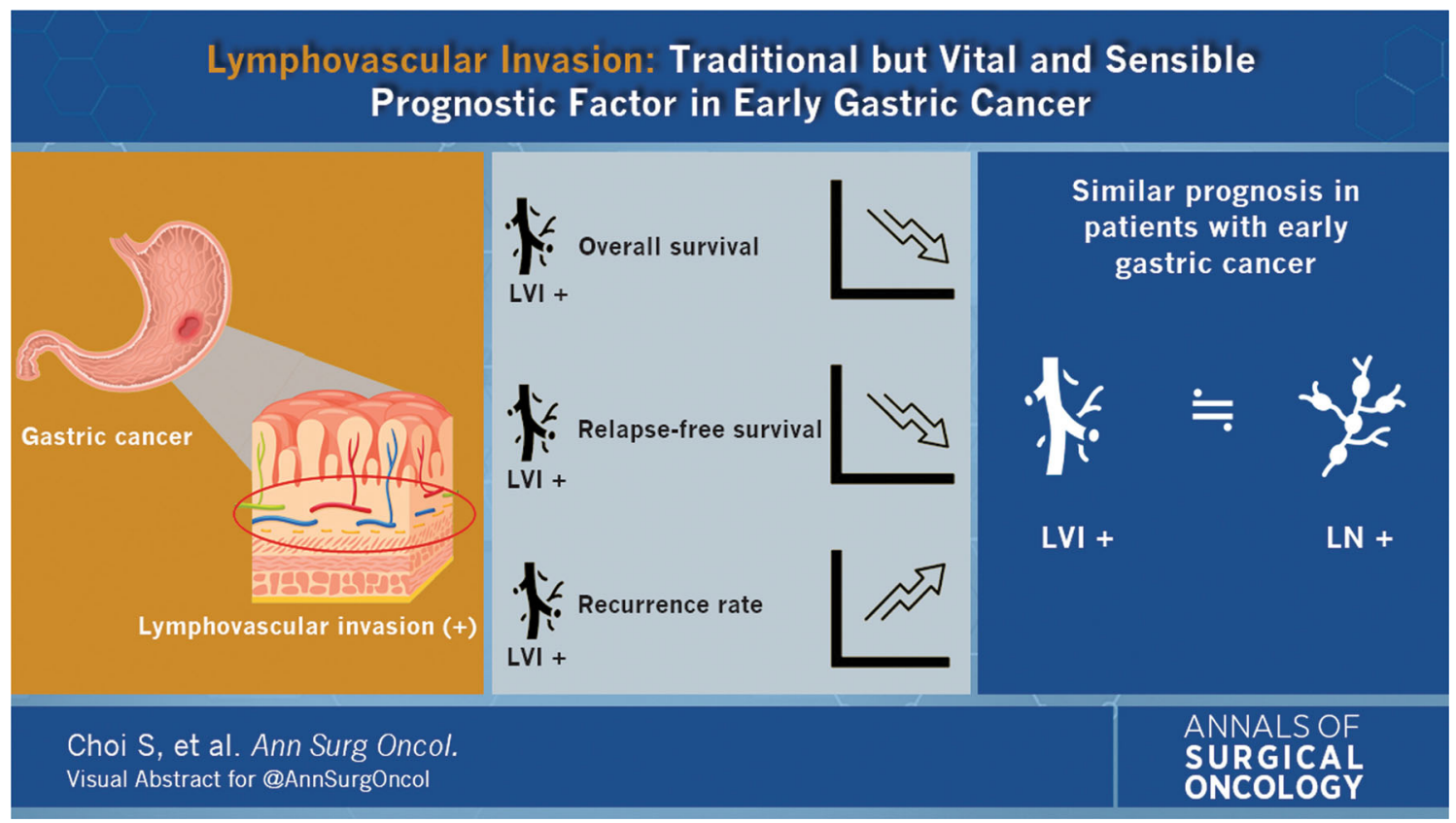

(C) Society of Surgical Oncology 2021

Published Online: 11 June 2021

W. J. Hyung, MD, PhD

e-mail: wjhyung@yuhs.ac
Sejin Lee, Minah Cho, Yoo Min Kim, and Hyoung-Il Kim report no conflicts of interest.

Publisher's Note Springer Nature remains neutral with regard to jurisdictional claims in published maps and institutional affiliations. 